\title{
Mental Health and its Influencing Factors Among Immigrants with Chronic Diseases in China
}

\author{
Jia Jia ${ }^{1} \cdot$ Xiao-Fei Nie ${ }^{1}\left[\mathrm{Li} \mathrm{Ke}^{1} \cdot\right.$ Bing Liu $^{1} \cdot$ Wen-Ru Wang ${ }^{1}$ \\ Accepted: 1 November 2021 / Published online: 9 January 2022 \\ (c) The Author(s), under exclusive licence to Springer Science+Business Media, LLC, part of Springer Nature 2021
}

\begin{abstract}
Immigrants are a special group in society, and their health is of great concern. Few studies have targeted this population in China. A cross-sectional descriptive correlational study was conducted from July to August 2018 in Hubei Province, China. Chi-square tests, Z-tests and multivariable linear regression analysis were performed to analyze the data using SPSS 24.0. A total of 1068 questionnaires were distributed. The results showed that the variables that affected the mental health of the immigrants with chronic diseases included gender, annual income, life events (L), negative emotion (NE), negative coping styles (NC) and objective support (OS) ( $\mathrm{p} \leq 0.05)$. Future research should focus on the physical and mental health of different immigrant groups and design effective, individualized interventions to improve the health status of immigrants, especially those with chronic diseases.
\end{abstract}

Keywords Mental health $\cdot$ Immigrants $\cdot$ Chronic diseases $\cdot$ Influencing factors

\section{Introduction}

The South-to-North Water Diversion Project is the largest water conservancy project in the world after the Three Gorges Project in China. As a result of this water conservancy project, which is located in Hubei Province, China, most nearby residents have immigrated to rural areas hundreds of kilometers away. The original living environment and social network structure of these immigrants have changed to varying degrees, which has led to psychological trauma. Immigrants constitute a special social group, and there are currently few studies on the health of immigrant

Xiao-Fei Nie

20190530@hbmu.edu.cn

Jia Jia

1215850473@qq.com

$\mathrm{Li} \mathrm{Ke}$

731413100@qq.com

Bing Liu

sy-lb@126.com

Wen-Ru Wang

nurww@nur.edu.sg

1 School of Nursing, Hubei University of Medicine, 30 Renmin South Rd., Shi Yan 422000, Maojian District, China groups, especially the mental health of immigrants with chronic disease.

Immigrants usually face significant stress across the entire migration period. There are some studies on Latino immigrants showing that each phase of the migration processpremigration, during migration and after migration-has unique risks that may differentially affect the mental health outcomes of immigrants [1,2]. During the premigration process, immigrants may be forced to migrate by factors beyond their control. Immigrants may refuse to migrate during this period and may be unable to accept the sudden news of relocation delivered by the government. During the migration phase, immigrants watch the environment where they lived for a long time be destroyed, which causes psychological trauma [3]. After migration, immigrants face many new issues, such as extended stays in detention centers, an unstable living environment, adaption to a new environment and interpersonal circle, acculturation challenges, daily living stressors and other different kinds of traumatic events, all of which could result in poor mental health outcomes for immigrants [4].

Immigrants are a special kind of group, and there are few studies on the health of immigrant groups at present. Some studies have explored the relationship between exposure to trauma during migration and the mental health status of immigrants; however, there are no unified or clear results. A 
survey among young Latino immigrants indicated that twothirds of youth experienced at least one traumatic event, and traumatic experience at different migration stages was associated with different mental health outcomes [1]. For example, trauma experienced during the premigration stage was significantly related to the anxiety of the immigrants. However, trauma experienced during any stage of the migration process did not predict depression independently. A focus group interview showed that the greatest health concern of Latino immigrants was mental health and wellbeing [5]. A survey on acculturation and mental health among vulnerable children and youth showed that there were no effects of social support on symptoms of posttraumatic stress disorder [6]. Most studies have focused specifically on the effects of premigration exposure to trauma among immigrants, but few studies have focused on the mental health problems and social support system of immigrants after resettlement.

Some studies have reported that during the early stage of migration to the new place of residence, immigrants have lower access to health service resources because of incomplete information and information at different stages of documentation [7, 8]. The reduction of health service resources has a direct and serious impact on the mental and physical health of immigrant residents. Exacerbated by a lack of local community health services, access to appropriate care and medical treatment is full of challenges due to language barriers, insufficient income, long waiting times, and inconvenient travel and public transportation conditions [9]. Moreover, social support is a key element that impacts the mental health of immigrants. Some studies have reported that immigrant residents are discriminated against by local residents when they came to the new environment, which makes it difficult to integrate into the new interpersonal circle and causes psychological problems [10,11]. Some studies have shown that some immigrants may commit suicide because of serious psychological problems $[12,13]$. Thus, access to medical care, the social support system and the acceptance of local residents seriously affect the health of immigrant residents.

Immigrants with chronic disease are another special group whose mental health problems deserve more attention from and exploration by scholars. There are studies showing that people with chronic diseases such as high blood pressure and diabetes have poor psychological resilience, and as a result, the ability of immigrant residents to adapt to their new environment is relatively poor, which causes a series of mental health issues [14, 15]. Immigrants with chronic disease need more health care and medical treatment provided by primary health services [16]. However, many studies have shown that immigrants have fewer opportunities to access primary health services, which delays the treatment of chronic diseases and causes anxiety in immigrants [17, 18]. It is important and necessary to explore the mental health situation and related factors of immigrants with chronic disease and to provide corresponding primary preventive care policy for immigrants. The purpose of this study was to explore the social support conditions, mental health status, psychosocial stress and the factors that influence the mental health of immigrants with chronic disease in Hubei Province, China.

\section{Methods}

\section{Study Design and Sample}

This study was an investigative study that was conducted from July to August 2018 by the research group. The sample consists of immigrants who moved from the Danjiangkou Reservoir Area in Shiyan City, Hubei Province, to Yun County, Danjiangkou City, Xiangzhou District, Yicheng City and Huangpi District. The sample size calculation formula is as follows: $\mathrm{N}=400 \times \mathrm{Q} / \mathrm{P}(\mathrm{Q}=1-\mathrm{P})$. Based on the results of the fifth national health service survey in 2013 , the prevalence rate of chronic diseases in the population aged 15 years and over was 33.1\% [19]. The test level was $\alpha=0.05, t=1.96$, and $P=0.331$, so the sample size was 808 . Because of response rate factors, the total sample size was 1068. A multistage stratified cluster sampling method was adopted. First, the towns with incoming migrants were randomly selected as the primary sampling units in 5 survey counties according to the following local economic development levels: good, medium, and poor. Randomly selected villages with immigrants from the selected townships were used as the subsampling units, and finally cluster sampling was performed. Eligible respondents were aged 15 years or older and had lived in the relocation place for 5 years or more. Immigrants who were deaf or mute, had an intellectual disability, or had severe cardiovascular or cerebrovascular diseases or mental illness were excluded. The study was reviewed and approved by the ethics review committee of our university in December 2017.

\section{Measures}

\section{General Demographic Characteristics Questionnaire}

The general demographic characteristics questionnaire collected general information (gender, age, ethnicity, marital status, education level, occupation, family income, etc.) and information on the prevalence of chronic diseases, family disease history, and medical security. 


\section{Psychological Stress}

The psychological stress of the immigrant residents was measured via the Psychosocial Stress Survey for Groups (PSSG) questionnaire. The PSSG was developed by Jiang in 1998 and is used for group psychological etiology analysis. This scale consists of 44 items in 5 dimensions, including life events (L), positive emotion (PE), positive coping styles (PC), negative emotion (NE), and negative coping styles (NC). The calculation method is 1 point for each item answered "yes" and 0 points for "no" or "no answer". The total stress score $(\mathrm{TS})=15+2 \times \mathrm{L}+3 \times \mathrm{NE}-\mathrm{PE}+5 \times \mathrm{NC}-\mathrm{P}$ $\mathrm{C}$. The higher the PSSG score is, the greater the individual's psychological pressure. The 4-week test-retest reliability of TS, L, PE, PC, NE, and NC were $0.88,0.70,0.83,0.62,0.80$, and 0.62 , respectively. The PSSG has been widely used in China [20].

\section{Social Support}

The social support of the immigrant residents was assessed using the Social Support Rating Scale (SSRS) questionnaire. The SSRS questionnaire was developed in 1994 by Xiao Shuiyuan, a mental health worker in China, on the basis of foreign scales. The scale consists of 10 items in three dimensions: objective support (OS), subjective support (SS), and utilization of support (US). Multilevel scoring is used, and the score of each index is obtained by adding the scores of the related indexes. The total score of the SSRS was 66, with a higher score indicating better social support. The retest reliability of the scale was 0.92 , and the consistency reliability of each item was 0.89-0.94 [21].

\section{Depressive and Anxiety Symptoms}

Depressive and anxiety symptoms were assessed using the Self-Report Symptom Inventory Symptom Checklist-90 (SCL-90), which was developed by Derogatis in 1973 [22]. The SCL-90 contains a wide range of psychiatric symptoms, from feeling, emotion, thinking, consciousness, and behavior to lifestyle habits, interpersonal relationships, diet, sleep, etc. The scale independently assesses the state of the selfbody, emotions, cognition, social function and spirit and consists of 90 items, each of which adopts a five-level scoring system. The scale consists of 9 factors: somatization, obsessive-compulsive, interpersonal sensitivity, depression, anxiety, hostility, phobic and paranoid ideation, and psychoticism. The SCL-90 has been translated into different languages, including Chinese. The Chinese version of the SCL-90 has good reliability and validity, with a Cronbach's alpha of 0.89 [23]. This scale is widely used in psychological counseling and psychotherapy in China and internationally, with a high degree of standardization.

\section{Quality Control}

In this study, a questionnaire survey was used. Most respondents completed the survey themselves, and the investigators offered assistance. That is, survey respondents could fill out the survey by themselves. If they could not, they were read the survey by the investigators. When the respondents completed the survey themselves, they were required to answer independently without interference; when the investigators assisted them, they asked the questions without subjectivity. The questionnaire was returned immediately after the questions were answered.

The investigators were strictly and uniformly trained before the start of the study. On the day of the completion of the survey, the investigator's self-inspection and the mutual inspection between the investigators were carried out and the omissions or illogical places were added or corrected in a timely manner. Before the formal investigation, the research group conducted a preinvestigation to make adjustments and improvements based on the problems found in the questionnaire in a timely manner, adjust the investigator's inquiry method and inquiry skills, and unify various standards to ensure the authenticity and reliability of the final investigation results. The data were entered twice and proofread for logic, and questionnaires with more than $20 \%$ of the questions missing were treated as invalid.

\section{Data Analysis}

SPSS 24.0 was used to analyze the data. General demographic data were converted into count data, and frequency $(\mathrm{N})$ and percentage (\%) were used for statistical description; the PSSG, SSRS and SCL-90 scores are presented as means and standard deviations. The chi-square test was used for the statistical analysis of the general data of immigrant residents with chronic disease and those without chronic disease; the Z-test was used for the statistical analysis of the PSSG, SSRS and SCL-90 scores of immigrant residents with chronic disease and those without chronic disease. The study employed single factor analysis and multivariable linear regression analysis to model effects on the mental health status of immigrant residents with chronic diseases. All analyses were carried out with two-sided tests $(\mathrm{P} \leq 0.05)$.

\section{Results}

A total of 1068 questionnaires were distributed, and 983 valid questionnaires were returned and analyzed, for a response rate of $92 \%$. 
There were 501 male immigrants and 482 female immigrants. The average age was $52.21 \pm 15.15$ years old.
The Differences in General Information Between Immigrants With or Without Chronic Diseases (Table 1)

There were 384 immigrants without chronic diseases and 599 immigrants with chronic diseases in this study. The variables that were significantly different between the two groups included age, gender, marital status, education level, occupation, family disease history, medical insurance and annual household income $(\mathrm{p} \leq 0.05)($ Table 1$)$.

Table 1 General information of immigrants with chronic diseases and immigrants without chronic diseases $(\mathrm{N}=983, \mathrm{n} \%)$

\begin{tabular}{|c|c|c|c|c|}
\hline Variable & $\begin{array}{l}\text { Immigrants with- } \\
\text { out chronic diseases } \\
(\mathrm{n}=384)\end{array}$ & $\begin{array}{l}\text { Immigrants with } \\
\text { chronic diseases } \\
(n=599)\end{array}$ & $\mathrm{X}^{2}$ & $P$ \\
\hline \multicolumn{5}{|l|}{ Gender } \\
\hline Male & $213(55.5)$ & $288(48.1)$ & 5.112 & $0.024^{*}$ \\
\hline Female & $171(44.5)$ & $311(51.9)$ & & \\
\hline \multicolumn{5}{|l|}{ Age (years) } \\
\hline $15-29$ & $85(22.1)$ & $10(1.7)$ & 211.661 & $<0.001^{* *}$ \\
\hline $30-44$ & $116(30.2)$ & $64(10.7)$ & & \\
\hline $45-59$ & $109(28.4)$ & $235(39.2)$ & & \\
\hline$\geqq 60$ & $74(19.3)$ & $290(48.4)$ & & \\
\hline \multicolumn{5}{|l|}{ Race } \\
\hline Han nationality & $384(94.8)$ & $576(96.2)$ & 1.048 & 0.306 \\
\hline Others & $20(5.2)$ & $23(3.8)$ & & \\
\hline Marital status & & & 51.452 & $<0.001^{* *}$ \\
\hline Unmarried & $53(13.8)$ & $15(2.5)$ & & \\
\hline Married & $319(83.1)$ & $541(90.3)$ & & \\
\hline Divorced or widowed & $12(3.1)$ & $43(7.2)$ & & \\
\hline Education level & & & 87.745 & $<0.001^{* *}$ \\
\hline Illiteracy & $56(14.6)$ & $186(31.1)$ & & \\
\hline Primary & $71(18.5)$ & $171(28.50$ & & \\
\hline Junior school & $153(39.8)$ & $188(31.4)$ & & \\
\hline High school and above & $104(27.1)$ & $54(9.0)$ & & \\
\hline Occupation & & & 39.176 & $<0.001^{* *}$ \\
\hline Farmer & $212(55.2)$ & $446(74.5)$ & & \\
\hline Others & $172(44.8)$ & $153(25.5)$ & & \\
\hline Family disease history & & & 11.694 & $0.001^{* *}$ \\
\hline No & $292(76.0)$ & $394(65.8)$ & & \\
\hline Yes & $92(24.0)$ & $205(34.2)$ & & \\
\hline Medical insurance & & & 7.994 & $0.005^{* *}$ \\
\hline Rural cooperative medical & $355(92.4)$ & $519(86.6)$ & & \\
\hline Employee health insurance & $29(7.6)$ & $80(13.4)$ & & \\
\hline Annual income & & & 4.866 & $0.027^{*}$ \\
\hline 2 times and below of PL & $138(35.9)$ & $259(43.2)$ & & \\
\hline 2-4 times of PL & $168(43.8)$ & 238(39.7) & & \\
\hline 4 times more than PL & $78(20.3)$ & 102(17.0) & & \\
\hline
\end{tabular}

Statistically significant differences: ${ }^{*} \mathrm{p} \leq 0.05 ;{ }^{* *} \mathrm{p} \leq 0.01$

PLPoverty Line:2300RMB per person per year in China (Available online: http://www.scio.gov.cn/37236/ 37262/Document/1599453/1599453.htm) 
Table 2 Scores of the PSSG, SSRS and SCL-90 of immigrants with and without chronic diseases $(\mathrm{N}=983, \mathrm{x} \pm \mathrm{s})$

\begin{tabular}{|c|c|c|c|c|c|c|c|c|}
\hline \multirow[t]{2}{*}{ Variable } & & \multirow[t]{2}{*}{ Median(IQI) } & \multicolumn{2}{|c|}{$\begin{array}{l}\text { Immigrants without chronic } \\
\text { diseases }(\mathrm{n}=384)\end{array}$} & \multicolumn{2}{|c|}{$\begin{array}{l}\text { Immigrants with chronic } \\
\text { diseases }(n=599)\end{array}$} & \multirow[t]{2}{*}{$\mathrm{Z}$} & \multirow[t]{2}{*}{$P$} \\
\hline & & & $\mathrm{x} \pm \mathrm{s}$ & Mean rank & $\mathrm{x} \pm \mathrm{s}$ & Mean rank & & \\
\hline \multirow[t]{6}{*}{ PSSG } & Life events (L) & $3(1-4)$ & $2.30 \pm 2.01$ & 415.29 & $3.03 \pm 1.84$ & 541.18 & -6.883 & $<0.001^{* *}$ \\
\hline & Positive emotion (PE) & $0(0-1)$ & $0.99 \pm 1.23$ & 553.42 & $0.63 \pm 1.10$ & 452.63 & -6.108 & $<0.001^{* *}$ \\
\hline & Negative emotion (NE) & $1(0-3)$ & $1.27 \pm 1.51$ & 426.10 & $2.06 \pm 2.11$ & 534.25 & -5.995 & $<0.001^{* *}$ \\
\hline & Positive coping styles (PC) & $2(1-4)$ & $2.92 \pm 2.29$ & 549.68 & $2.26 \pm 2.18$ & 455.02 & -5.199 & $<0.001^{* *}$ \\
\hline & Negative coping styles (NC) & $1(0-3)$ & $1.48 \pm 1.85$ & 468.48 & $1.69 \pm 1.84$ & 507.08 & -2.158 & $0.031^{*}$ \\
\hline & PSSG total score & $27(20-38)$ & $26.90 \pm 13.87$ & 419.06 & $32.83 \pm 15.49$ & 538.76 & -6.451 & $<0.001^{* *}$ \\
\hline \multirow[t]{4}{*}{ SSRS } & Objective support (OS) & $10(8-11)$ & $9.37 \pm 2.13$ & 465.38 & $9.60 \pm 2.22$ & 509.07 & -2.389 & $0.017^{* *}$ \\
\hline & Subjective support (SS) & $20(17-23)$ & $20.55 \pm 4.11$ & 530.36 & $19.64 \pm 4.04$ & 467.41 & -3.401 & $0.001^{* *}$ \\
\hline & Utilization of support (US) & $6(5-8)$ & $6.75 \pm 2.08$ & 528.58 & $6.34 \pm 2.25$ & 468.55 & -3.264 & $0.001^{* *}$ \\
\hline & SSRS total score & $36(32-40)$ & $36.66 \pm 6.38$ & 520.67 & $35.58 \pm 6.36$ & 473.62 & -2.538 & $0.001^{* * *}$ \\
\hline \multirow[t]{11}{*}{ SCL-90 } & Somatization & $17(14-22)$ & $1.25 \pm 0.31$ & 314.48 & $1.74 \pm 0.55$ & 605.80 & -15.754 & $<0.001^{* *}$ \\
\hline & Obsessive-compulsive & $12(11-14)$ & $1.25 \pm 0.33$ & 409.80 & $1.37 \pm 0.37$ & 544.70 & -7.345 & $<0.001^{* *}$ \\
\hline & Interpersonal sensitivity & $9(9-10)$ & $1.10 \pm 0.24$ & 471.49 & $1.14 \pm 0.27$ & 505.15 & -2.164 & $0.030^{*}$ \\
\hline & Depression & $14(13-17)$ & $1.16 \pm 0.29$ & 414.87 & $1.28 \pm 0.39$ & 541.45 & -7.031 & $<0.001^{* *}$ \\
\hline & Anxiety & $11(10-13)$ & $1.13 \pm 0.23$ & 400.97 & $1.28 \pm 0.37$ & 55.36 & -8.355 & $<0.001^{* *}$ \\
\hline & Hostility & $6(6-7)$ & $1.14 \pm 0.30$ & 463.64 & $1.20 \pm 0.36$ & 510.18 & -2.853 & $0.004^{* * *}$ \\
\hline & Phobic anxiety & $7(7-7)$ & $1.06 \pm 0.17$ & 473.06 & $1.10 \pm 0.29$ & 504.14 & -2.309 & $0.021^{*}$ \\
\hline & Paranoiel ideation & $6(6-6)$ & $1.09 \pm 0.19$ & 497.28 & $1.09 \pm 0.22$ & 488.62 & -0.637 & 0.524 \\
\hline & Psychotism & $10(10-11)$ & $1.06 \pm 0.16$ & 440.75 & $1.11 \pm 0.23$ & 524.85 & -5.462 & $<0.001^{* *}$ \\
\hline & Additional factor & $9(7-12)$ & $1.29 \pm 0.36$ & 374.24 & $1.59 \pm 0.49$ & 567.49 & -10.541 & $<0.001^{* *}$ \\
\hline & SCL-90 total score & $106(97-121)$ & $104.41 \pm 17.46$ & 356.67 & $118.06 \pm 25.87$ & 578.76 & -11.970 & $<0.001^{* *}$ \\
\hline
\end{tabular}

Statistically significant differences: ${ }^{*} \mathrm{p} \leq 0.05 ;{ }^{* *} \mathrm{p} \leq 0.01$

PSSG Psychosocial Stress Survey for Groups, SSRS Social Support Rating Scale, SCL-90 Self-Report Symptom Inventory, Symptom CheckList90

\section{The Differences in the PSSG, SSRS and SCL-90 Scores Between Immigrants With or Without Chronic Diseases (Table 2)}

The total PSSG, SSRS and SCL-90 scores of the immigrants without chronic diseases were $26.90 \pm 13.87$, $36.66 \pm 6.38$, and $104.41 \pm 17.46$, respectively. The total PSSG, SSRS and SCL-90 scores of the immigrants with chronic diseases were $32.83 \pm 15.49,35.58 \pm 6.36$, and $118.06 \pm 25.87$, respectively. There were statistically significant differences in psychological stress, social support and depressive and anxiety symptoms between the immigrants with chronic diseases and immigrants without chronic diseases $(\mathrm{p} \leq 0.05)$ (Table 2).

\section{The Influencing Factors in Immigrants with Chronic Diseases (Tables 3 \& 4)}

The variables that significantly affected the SCL-90 total score of the immigrants with chronic diseases included gender, occupation, family disease history and annual income, according to the single factor analysis $(\mathrm{p} \leq 0.05)$ (Table 3). When performing multiple linear regression analysis on these statistically significant factors, the PSSG score and the SSRS score together, the results showed 
Table 3 Single factor analysis of mental health of immigrant patients with chronic diseases $(\mathrm{n}=599, \mathrm{x} \pm \mathrm{s})$

\begin{tabular}{|c|c|c|c|}
\hline Variable & SCL-90 total score $(-\mathrm{x} \pm \mathrm{s})$ & $\mathrm{t} / \mathrm{F}$ & $P$ \\
\hline Gender & & 9.366 & $0.002^{* *}$ \\
\hline Male & $114.72 \pm 24.26$ & & \\
\hline Female & $121.15 \pm 26.94$ & & \\
\hline Age (years) & & 0.233 & 0.873 \\
\hline $15-29$ & $118.90 \pm 21.08$ & & \\
\hline $30-44$ & $116.94 \pm 38.33$ & & \\
\hline $45-59$ & $119.12 \pm 28.09$ & & \\
\hline$\geqq 60$ & $117.42 \pm 20.24$ & & \\
\hline Race & & 0.439 & 0.508 \\
\hline Han nationality & $117.92 \pm 26.01$ & & \\
\hline Others & $121.57 \pm 22.24$ & & \\
\hline Marital status & & 1.108 & 0.331 \\
\hline Unmarried & $121.13 \pm 29.98$ & & \\
\hline Married & $117.55 \pm 24.37$ & & \\
\hline Divorced or widowed & $123.35 \pm 39.48$ & & \\
\hline Education level & & 1.662 & 0.174 \\
\hline Illiteracy & $120.50 \pm 25.87$ & & \\
\hline Primary & $118.09 \pm 24.43$ & & \\
\hline Junior school & $117.43 \pm 28.66$ & & \\
\hline High school and above & $111.76 \pm 18.35$ & & \\
\hline Occupation & & 5.641 & $0.018^{*}$ \\
\hline Farmer & $119.52 \pm 27.08$ & & \\
\hline Others & $113.79 \pm 21.47$ & & \\
\hline Family disease history & & 7.982 & $0.005^{* *}$ \\
\hline No & $115.92 \pm 20.77$ & & \\
\hline Yes & $122.18 \pm 33.24$ & & \\
\hline Medical insurance & & 1.113 & 0.292 \\
\hline Rural cooperative medical & $117.62 \pm 24.48$ & & \\
\hline Employee health insurance & $120.90 \pm 33.53$ & & \\
\hline Annual income & & 7.892 & $<0.001^{* *}$ \\
\hline 2 times and below of PL & $113.48 \pm 15.42$ & & \\
\hline 2-4 times of PL & $120.57 \pm 22.79$ & & \\
\hline 4 times more than PL & $123.83 \pm 45.08$ & & \\
\hline
\end{tabular}

Statistically significant differences: ${ }^{*} \mathrm{p} \leq 0.05 ;{ }^{* *} \mathrm{p} \leq 0.01$

$\mathrm{PL}=$ Poverty Line:2300RMB per person per year in China(Available online: http://www.scio.gov.cn/37236/ 37262/Document/1599453/1599453.htm)
Table 4 Multivariable linear regression analysis of influencing factors of mental health of immigrants with chronic diseases $(n=599)$

\begin{tabular}{lrlllr}
\hline Variable & $B$ & S.E & Beta & \multicolumn{2}{l}{$P$} \\
\hline Gender & 4.180 & 1.728 & 0.081 & 2.419 & $0.016^{*}$ \\
Annual income & 3.848 & 1.183 & 0.109 & 3.253 & $0.001^{* *}$ \\
Life events (L) & 3.633 & 0.708 & 0.259 & 5.130 & $<0.001^{* *}$ \\
Negative emotion (NE) & 4.980 & 0.485 & 0.406 & 10.263 & $<0.001^{* *}$ \\
Negative coping styles & 1.578 & 0.529 & 0.112 & 2.985 & $0.003^{* *}$ \\
$\quad$ NC) & & & & & \\
Objective support (OS) & -1.986 & 0.593 & -0.170 & -3.348 & $0.001^{* *}$ \\
\hline
\end{tabular}

Statistically significant differences: ${ }^{*} \mathrm{p} \leq 0.05 ;{ }^{* *} \mathrm{p} \leq 0.01$ that the variables that were significantly different included gender, annual income, life events (L), negative emotion (NE), negative coping styles (NC) and objective support (OS) $(\mathrm{p} \leq 0.05)($ Table 4).

\section{Discussion}

The Prevalence of Chronic Diseases Among Immigrant Residents

This study showed that the prevalence of chronic diseases 
among immigrant residents was $60.94 \%$, which was higher than other research results. A 17-year National Health Interview Survey (1999-2015) identified that the prevalence of chronic diseases among Mexican, Puerto Rican, Cuban, Dominican, and Central/South American immigrants was $23.1 \%, 40.0 \%, 38.5 \%, 28.0 \%$ and $23.5 \%$, respectively [16]. A cross-sectional health condition analysis of immigrants from Iraq and Afghanistan to the United States between 2009 and 2017 showed that $56.5 \%$ of these immigrants were overweight or obese, $2.4 \%$ reported hypertension and $1.1 \%$ reported diabetes [24]. In this study, the reasons for the high incidence of chronic diseases among Chinese immigrants include the following. First, the average age of the participants in this study was older than that in the other two studies $[16,24]$. The average age in this study was 52.21 years; however, only $7.4 \%$ of the participants were aged 45-64 years in the study of Kumar, and the average age was 42.02 years in the study of Lo. Chronic diseases are indeed more common in the elderly. Second, there is a large elderly population in China, and most of them are empty nesters. When the research group conducted the survey, most adults worked away from home to cover family living expenses. The family living conditions of the group as a whole were relatively poor, and the immigrants had not adapted to the food culture of the new area, which affected their daily life and diet. Another study showed that appropriate dietary strategies can help reduce the risk of chronic disease in Chinese immigrant communities [25].

\section{The Social Support Status of Immigrant Residents}

This study showed that the subjective support and utilization of support levels of immigrants with chronic diseases were lower than those of immigrants without chronic diseases, but the level of objective support of immigrants with chronic diseases was higher than that of immigrants without chronic diseases. The social support total score was relatively low for immigrants regardless of whether the immigrants had chronic diseases. With the development and progress of medical treatment, the community can support chronic disease management for patients with chronic diseases, so the immigrants' objective support was relatively high compared with that of immigrants without a chronic disease. However, the utilization rate of medical resources of migrant residents with chronic diseases was still relatively low, as confirmed by many studies. The California Health Interview Survey results also showed that immigrants have lower levels of health service utilization and fewer health care visits [2]. A study of 100 Latino immigrants residing in Tennessee reported that females, immigrants who are not married/cohabiting, and those who reported experiencing a greater number of discrete stressors in the USA each reported lower levels of social support [26]. A study among
Asian American immigrants showed that among all Asian American immigrants, high family social support decreased levels of psychological distress [27]. Many studies have reported that immigrants have a low level of social support and that social support conditions affect mental stress, health and daily life. A cross-sectional study among recent Latino immigrants showed that social support was protective against immigration stress [28]. A study among immigrants in Spain suggested that support networks involving family and native friends and integration into the community were important influences that improved immigrants' life satisfaction [29]. These study findings highlight the importance of social support among immigrants while also drawing attention to the different social support levels of different immigrant subgroups.

\section{The Psychological Stress of Immigrant Residents}

The immigrants with chronic diseases had a higher level of psychological stress than the immigrants without chronic diseases in the present study. The immigrants with chronic diseases had high scores for life events (L) and negative emotion (NE). A study among Latina immigrants also showed that immigrants were at increased risk for poor mental health [30]. Regarding the reason for this, migrants with chronic diseases not only experience the trauma of relocation-related events but also experience the psychological stress of physical chronic diseases, so immigrants with chronic diseases have more negative emotions and high psychological stress. A study showed that discrimination and acculturation were identified as important stressors and caused high psychological stress in immigrants [31]. A study conducted with a U.S.-based representative sample of Asian $(n=1637)$ and Latino $(n=1620)$ immigrants also showed that the immigrants had higher psychological stress, especially the chronic disease group, and that traumatic events in the migration process, discrimination, acculturative stress, and family conflict increased the risk for psychological distress among immigrants [32]. Another study suggested that immigrant groups vary widely in their mental health outcomes, but the risk diminishes over time, and racial and ethnic background affects their psychological stress [33]. High psychological stress not only affects immigrants themselves negatively but also influences the education and growth of their children. A national epidemiological study in Taiwan showed that compared with children of native mothers, children of immigrant mothers reported themselves and were reported by their parents to have more externalizing and internalizing problems, and social demographics, parenting style, and family function affected the characteristics of the children of immigrants [34]. A study in Australia among immigrant women showed that immigrant and refugee women from diverse ethnic backgrounds encountered multiple barriers 
in accessing mental healthcare in various settings, which also caused high psychological stress in this specific group [35]. Thus, it can be seen that the psychological stress problems of immigrants influence their whole family and society. Therefore, local governments should support research on specific immigrant groups, evaluate transcultural policies, improve medical services, and implement claims policies and social integration systems for immigrants to reduce their psychological stress.

\section{The Factors Influencing the Mental Health Status of Immigrants with Chronic Diseases}

The results of this study showed that immigrants with and immigrants without chronic diseases had high SCL-90 scores, which suggested that our participants had a poor mental health status. Moreover, the depression and anxiety symptoms of immigrants with chronic diseases were more serious and severe than those of immigrants without chronic diseases. An investigation among Haitian migrants in southern Brazil showed that the posttraumatic stress disorder (PTSD) prevalence in the sample was 9.1\%; depression and anxiety symptoms were in the clinical range for $10.6 \%$ and $13.6 \%$ of participants, respectively [36]. A Canadian longitudinal study identified that immigrants who experienced depressive symptoms accounted for $15.9 \%$ of the sample and that women were more likely to experience depression than men [37]. A survey among American immigrant mothers showed that the majority of mothers (74.6\%) had experienced a traumatic life event, with $43.3 \%$ experiencing trauma symptoms indicative of PTSD [38]. A study among immigrant groups from different countries suggested that compared to Mexican immigrants, Cuban and Dominican immigrants reported higher odds of depressive symptoms and Haitian and Jamaican immigrants reported lower odds of depressive symptoms; female immigrants had higher odds of reporting depressive symptoms than their male counterparts; and relative to immigrants with good childhood health, those with unfavorable childhood health had higher odds of reporting worse health outcomes [39]. In the present study, immigrants experienced different mental health problems, such as depression, anxiety and even PTSD. The different groups of immigrants also experienced varying degrees of depression and anxiety symptoms. Scientists should pay more attention to the mental health problems of immigrants, provide more personalized interventions and call for the promotion of policies suited to different groups of immigrants.

The present study also analyzes the factors influencing the mental health of immigrants with chronic diseases. The results showed that gender, annual income, life events (L), negative emotion (NE), negative coping styles (NC) and objective support (OS) were factors related to the mental health of immigrants with chronic diseases. This study showed that females had a higher SCL-90 score and experienced more serious depressive symptoms. This result was consistent with the findings of many other studies. The study of Abdul-Malak found that female immigrants had higher odds of reporting depressive symptoms than males [39]. A qualitative study conducted among married immigrant women in Korea identified that immigrant women had a high rate of mental health problems [40]. A literature review also suggested that future research should focus on how women's personal attributes interact with macrolevel, sociocultural contexts, including familial relationships and the community social support system, and future evidence-based policy and interventions should comprehensively address married immigrant women's sociocultural, economic and mental health needs [41]. There are many reasons why female immigrants have a high risk of depressive symptoms. For example, women may become pregnant and give birth, and during this process, they are a high-risk group for depression and anxiety. In some countries, women usually stay at home to take care of the whole family, and they may not have any income, which may affect their mental health status.

The income of the whole family was another factor that influenced the mental health condition of immigrants with chronic diseases. This survey found that the higher the per monthly income of the family, the higher the degree of depression among immigrants with chronic diseases was. This finding differs from the results of other research. A longitudinal study of humanitarian migrants in Australia found that immigrants who had high incomes and good social integration were at lower risk for mental diseases [42]. A systematic review found that immigrants who had a high family income had a lower risk of depression and anxiety symptoms [43]. The present study found the opposite. Because there were so many elderly empty nesters, the mean age in this study was high. In the process of the investigation, most of the elderly completed the questionnaire at home. For the elderly empty nesters, although their children worked outside and could make sufficient money for the family, this led to a lack of their children's companionship and care. Those elderly individuals also had various chronic diseases, and they needed the care and companionship of their children. However, these elderly immigrants with chronic diseases had poor family support even though they had high family income. This poor family support affected the mental health status of the immigrants with chronic diseases.

Life events (L), negative emotion (NE) and negative coping styles (NC) can influence the mental health status of immigrants with chronic diseases. The immigrants with chronic diseases who experienced more life trauma events, had more negative emotions and lacked negative coping styles were at higher risk of depression and anxiety. Many studies have reported the same outcomes. A study among Latina immigrant women found that immigrant women who 
experienced employment discrimination, recent unstable housing and deportation were more likely to have mental health problems [44]. A study among Somali immigrants showed that immigrants who experienced more racial discrimination and cultural maladjustment were at high risk of mental health issues and used the health care system less [45]. One study showed that decreasing negative emotions was an effective method to improve the mental health status of immigrants with chronic diseases [46]. A study among English-speaking Asian American immigrant families found that immigrant families that had fewer traumatic life events related to the immigration process, less negative emotions, and more positive coping styles had a relatively good psychological state and lifestyle [47]. In other words, immigrants with chronic diseases who experience a smooth relocation process and fewer traumatic events can adapt well to the culture and environment of the new residence. Immigrants with chronic diseases who can deal with negative emotions and traumatic events in a positive way may have better psychological status.

Objective support (OS) affects the mental health condition of immigrants with chronic diseases as well. A longitudinal cohort study conducted from 1996 to 2012 in Canada showed that the better the objective support systems, such as the public health services system, where immigrants live, the better the physical and psychological condition of immigrant residents with chronic diseases were [9]. A study in Norway concluded that if the primary health care services systems of the local immigrants were comprehensive and perfect, the utilization of the health care services of the immigrants was high, and their physical and mental health was good [48]. A study in Canada also suggested that immigrants with chronic diseases had complex psychological problems, which may be related to the inadequate local medical objective support system [49]. A study among Chinese immigrants showed that family and friend support, medical service support, and local government support were the main sources of support for immigrants. These objective support systems benefitted the mental health and physical health of the immigrants, especially those with certain diseases [50]. Objective support was a main factor that influenced the mental health of immigrants with chronic diseases. Objective support includes many aspects, such as family and friend support, local medical support, government support and the friendly attitude of the local people. To improve the health status of immigrants with chronic diseases, society as a whole should make a united effort and contribution, including medical staff, government workers and local residents. The medical department should improve its disease management systems and provide excellent service for immigrants; the government should improve its policy on immigrant residents and provide some welfare assistance for them; and the local residents should accept and be friendly to immigrant residents.
There is much research on the mental health of elderly patients with chronic diseases in China and even around the world. The results of a large-sample study showed that the detection rate of depression in elderly patients with chronic diseases was 37.02\% [51]. In addition, the research data from the China Health and Senior Care Tracking Survey Project showed that the overall detection rate of depression in elderly patients with chronic diseases was as high as $40.3 \%$ [52]. However, in recent years, the government has also taken corresponding measures to improve the health problems of patients with chronic diseases. For example, against the background of family doctors signing service contracts, the psychological condition of elderly patients with chronic diseases in the community was investigated and analyzed. The results showed that the detection rates of anxiety and depression in elderly patients with chronic diseases were $13.77 \%$ and $22.83 \%$, respectively [53]. The mental health of Chinese elderly patients with chronic diseases is still a common problem. At present, there are few studies focusing on the mental health of immigrants in China. However, there is evidence that relocation-related stressors can affect the mental health of immigrants [50]. The social factors of immigration and relocation only worsen the mental health of immigrants with chronic disease. A survey among young Latino immigrants indicated that two-thirds of youth experienced mental health problems [1]. The mental health of immigrants was worse than that of ordinary elderly patients with chronic diseases. Immigrant groups need to adapt to a new living environment and rebuild their social relationships. When immigrants arrive in a new living environment, if their medical services, economic income and social support are not adequate, their physical and mental health will inevitably become important issues that society needs to solve. Therefore, the mental health problems of immigrant groups with chronic diseases are more serious than those of ordinary people with chronic diseases, and more attention is needed from scholars and medical staff in the future.

To improve the health condition of immigrants with chronic diseases, society as a whole should make a united effort and contribute, including medical staff, government workers and local residents. First, the government needs to strengthen the functions of primary medical and health services for immigrant residents and strengthen chronic disease prevention and care for the elderly. For example, primary medical and health institutions should assume responsibility for preventing and controlling various chronic diseases in the elderly and use the family doctor system to manage various chronic diseases; the community health care center should improve primary care for the elderly, reduce the incidence of diseases and delay the decline in the self-care ability of elderly immigrants; and the medical staff in the community should actively carry out health education and psychological consultation for immigrants to effectively 
prevent and control chronic diseases. Second, society needs to improve the income security system of immigrant groups and improve the economic conditions of elderly immigrants. Third, the government needs to strengthen the cultural offerings for the elderly population in places where immigrant groups live in order to increase opportunities for immigrants to express themselves and communicate and increase the social support available to immigrants. Moreover, the local government needs to improve the elderly care service system based on the home, supported by the community, supplemented by institutions, and combined with medical care. Finally, society as a whole should reduce discrimination against immigrant residents, provide better medical resources and benefits, and allow immigrants to integrate more quickly into their new place of residence.

\section{Implications for Future Research}

The present study discussed only the mental health condition of immigrants and the factors related to the mental health of immigrants with chronic diseases. In fact, immigrants have many health problems that need our attention. First, the reconstruction of social relations is an important issue among immigrant groups, and social relations also affect the health of immigrants; therefore, future research can pay more attention to the reconstruction of social relations and the relationship issues encountered among immigrant groups. Second, quality of life is another important issue for immigrants, and future studies can carry out long-term follow-up studies to observe the long-term quality of life of immigrant groups. Third, future studies could also pay attention to the posttraumatic growth of immigrants and explore the related factors to develop intervention measures to promote the mental health of immigrant groups. Moreover, in light of the current COVID-19 pandemic, there were no findings on whether COVID-19 disproportionally affected the mental health of immigrants with chronic physical diseases. Therefore, future studies could also discuss the impact of the COVID-19 epidemic on the health of immigrant residents.

\section{Conclusion}

Many immigrants in Hebei Province, China, have been displaced by the South-to-North Water Diversion Project. These immigrants are a special group, and their health is an important problem for the medical department. However, few scientific researchers have paid attention to this group. This study investigated 983 immigrants in Hubei Province and found that they had serious psychological stress and mental health problems, especially those with chronic diseases. Gender, annual income, life events (L), negative emotion (NE), negative coping styles
(NC) and objective support (OS) were factors related to the mental health of immigrants with chronic diseases. Future research should pay attention to the physical and mental health of different immigrant groups and design individualized and effective interventions to improve the health status of immigrants, especially those with chronic diseases.

Acknowledgements We would like to thank all the participants in the research and the investigating local government workers for their help and support. We would also like to thank all the experts and researchers who gave wonderful advice on this article.

\section{Declarations}

Conflict of interest None.

\section{References}

1. Cleary SD, et al. Immigrant trauma and mental health outcomes among Latino youth. J Immigr Minor Health. 2018;20(5):1053-9. https://doi.org/10.1007/s10903-017-0673-6.

2. Seo JY, et al. Disparities in health care utilization between Asian immigrant women and non-hispanic white women in the United States. J Womens Health (Larchmt). 2019;28(10):1368-77. https://doi.org/10.1089/jwh.2018.7532.

3. Sampathi BR. Asian mental health and use of drama therapy for acculturative family distancing in immigrant families. Ment Illn. 2018;10(2):7806-15. https://doi.org/10.4081/mi.2018.7806.

4. Vered Y, et al. Psychological distress and social support are determinants of changing oral health status among an immigrant population from Ethiopia. Community Dent Oral Epidemiol. 2011;39(2):145-53. https://doi.org/10.1111/j.1600-0528.2010. 00581.x

5. Siemons R, et al. Coming of age on the Margins: mental health and wellbeing among Latino immigrant young adults eligible for deferred action for childhood arrivals (DACA). J Immigr Minor Health. 2017;19(3):543-51. https://doi.org/10.1007/ s10903-016-0354-x.

6. Oppedal B, Idsoe T. The role of social support in the acculturation and mental health of unaccompanied minor asylum seekers. Scand J Psychol. 2015;56(2):203-11. https://doi.org/10.1111/sjop. 12194.

7. Ganann R, et al. Influences on mental health and health services accessibility in immigrant women with post-partum depression: An interpretive descriptive study. J Psychiatr Ment Health Nurs. 2019;27:1-10. https://doi.org/10.1111/jpm.12557.

8. Salami B, Salma J, Hegadoren K. Access and utilization of mental health services for immigrants and refugees: Perspectives of immigrant service providers. Int J Ment Health Nurs. 2019;28(1):152-61. https://doi.org/10.1111/inm.12512.

9. Saunders NR, et al. Trends in mental health service utilization in immigrant youth in Ontario, Canada, 1996-2012: a populationbased longitudinal cohort study. BMJ Open. 2018;8(9): e022647. https://doi.org/10.1136/bmjopen-2018-022647.

10. Chae SM, Park JW, Kang HS. Relationships of acculturative stress, depression, and social support to health-related quality of life in Vietnamese immigrant women in South Korea. J Transcult Nurs. 2014;25(2):137-44. https://doi.org/10.1177/1043659613 515714. 
11. Rhodes SD, et al. Social support among immigrant Latino men: a validation study. Am J Health Behav. 2013;37(5):620-8. https:// doi.org/10.5993/AJHB.37.5.5.

12. Fortuna LR, et al. Mental health, migration stressors and suicidal ideation among Latino immigrants in Spain and the United States. Eur Psychiatr. 2016;36(12):15-22. https://doi.org/10.1016/j. eurpsy.2016.03.001.

13. George $U$, et al. Immigrant mental health, a public health issue: looking back and moving horward. Int J Environ Res Public Health. 2015;12(10):13624-48. https://doi.org/10.3390/ijerp h121013624.

14. Islam F, Oremus M. Mixed methods immigrant mental health research in Canada: a systematic review. J Immigr Minor Health. 2014;16(6):1284-9. https://doi.org/10.1007/s10903-013-9962-x.

15. Sia D, et al. Chronic disease and malnutrition biomarkers among unemployed immigrants and Canadian born adults. Arch Public Health. 2019;77(13):41-51. https://doi.org/10.1186/ s13690-019-0367-8.

16. Lo CC, Adame JL, Cheng TC. Explaining chronic illness and self-rated health among immigrants of five hispanic ethnicities. J Racial Ethn Health Disparities. 2019;12(4):125-31. https://doi. org/10.1007/s40615-019-00647-z.

17. Choi YJ. Effects of a program to improve mental health literacy for married immigrant women in Korea. Arch Psychiatr Nurs. 2017;31(4):394-8. https://doi.org/10.1016/j.apnu.2017.04.012.

18. Kayser M, et al. Chronic progressive pulmonary paracoccidioidomycosis in a female immigrant from Venezuela. Ther Adv Respir Dis. 2019;20(13):1-6. https://doi.org/10.1177/1753466619 894913.

19. Ling X, Qun M. Findings of the fifth national health services survey II-health service needs, needs and utilization. Chin J Health Inf Manag. 2014;11(3):193-4. https://doi.org/10.3969/j.issn.16725166.2014.03.01.

20. Jiang QJ. A preliminary study on the comprehensive evaluation of psychosocial stress factors. Chin J Behav Med Sci. 1998;7(3):182-4.

21. Xiao SY. The theoretical basis and research application of the Social Support Rating Scale. J Clin Psychol. 1994;4(2):98-100.

22. Derogatis LR, Lipman RS, Covi L. SCL-90: an outpatient psychiatric rating scale-preliminary report. Psychopharmacol Bull. 1973;9(1):13-28.

23. Wang ZY. The self-report symptom inventory, symptom checkList90. Shanghai Psychiatr. 1948;2(17):68-70.

24. Kumar GS, et al. Health profile of adult special immigrant visa holders arriving from Iraq and Afghanistan to the United States, 2009-2017: a cross-sectional analysis. PLoS Med. 2020;17(5): e1003118. https://doi.org/10.1371/journal.pmed.1003118.

25. Kirshner LY, et al. Acculturation and diet among Chinese American immigrants in New York City. Nutr Epidemiol Public Health. 2020;4(1):nzz124. https://doi.org/10.1093/cdn/nzz124.

26. Held ML. Correlates of social support among Latino immigrants. J Racial Ethn Health Disparities. 2018;5(2):422-9. https://doi.org/ 10.1007/s40615-017-0385-6.

27. Singh S, McBride K, Kak V. Role of social support in examining acculturative stress and psychological distress among Asian American immigrants and three sub-groups: results from NLAAS. J Immigr Minor Health. 2015;17(6):1597-606. https://doi.org/10. 1007/s10903-015-0213-1.

28. Sanchez M, et al. Immigration stress among recent Latino immigrants: the protective role of social support and religious social capital. Soc Work Public Health. 2019;34(4):279-92. https://doi. org/10.1080/19371918.2019.1606749.

29. Hombrados-Mendieta I, et al. Positive influences of social support on sense of community, life satisfaction and the health of immigrants in Spain. Front Psychol. 2019;12(10):2555-72. https://doi. org/10.3389/fpsyg.2019.02555.
30. Ryan D, et al. Amigas Latinas Motivando el Alma (ALMA): an evaluation of a mindfulness intervention to promote mental health among Latina immigrant mothers. J Behav Health Serv Res. 2018;45(2):280-91. https://doi.org/10.1007/s11414-017-9582-7.

31. Szaflarski M, Bauldry S. The effects of perceived discrimination on immigrant and refugee physical and mental health. Adv Med Sociol. 2019;19(3):173-204. https://doi.org/10.1108/S1057629020190000019009.

32. Sangalang CC, et al. Trauma, post-migration stress, and mental health: a comparative analysis of refugees and immigrants in the United States. J Immigr Minor Health. 2019;21(5):909-19. https:// doi.org/10.1007/s10903-018-0826-2.

33. Lee R. Does the healthy immigrant effect apply to mental health? Examining the effects of immigrant generation and racial and ethnic background among Australian adults. SSM Popul Health. 2019;7(16):11-20. https://doi.org/10.1016/j.ssmph.2018.10.011.

34. Chang JC, et al. The mental health of immigrant mother's offspring in Taiwan: A national epidemiological study. J Formos Med Assoc. 2019;8(33):1-9. https://doi.org/10.1016/j.jfma.2019. 08.033.

35. Wohler Y, Dantas JA. Barriers accessing mental health services among culturally and linguistically diverse (CALD) immigrant women in Australia: policy implications. J Immigr Minor Health. 2017;19(3):697-701. https://doi.org/10.1007/s10903-016-0402-6.

36. Brunnet AE, et al. Prevalence and factors associated with PTSD, anxiety and depression symptoms in Haitian migrants in southern Brazil. Int J Soc Psychiatry. 2018;64(1):17-25. https://doi.org/10. 1177/0020764017737802.

37. Davison KM, et al. Depression in middle and older adulthood: the role of immigration, nutrition, and other determinants of health in the Canadian longitudinal study on aging. BMC Psychiatry. 2019;19(1):329-50. https://doi.org/10.1186/s12888-019-2309-y.

38. Letiecq BL, et al. Central American immigrant mothers' mental health in the context of illegality: structural stress, parental concern, and trauma. Fam Community Health. 2019;42(4):271-82. https://doi.org/10.1097/FCH.0000000000000233.

39. Abdul-Malak Y. Healthy immigrants? exploring depressive symptoms among Caribbean and Mexican immigrants. J Racial Ethn Health Disparities. 2019;17(20):445-51. https://doi.org/10.1007/ s40615-019-00677-7.

40. Choi YJ. Mental health problems and acculturative issues among married immigrant women in Korea: A qualitative study. Women Health. 2016;56(6):713-29. https://doi.org/10.1080/03630242. 2015.1118724.

41. Lee $\mathrm{Y}$, Park S. The mental health of married immigrant women in South Korea and its risk and protective factors: A literature review. Int J Soc Psychiatr. 2018;64(1):80-91. https://doi.org/10. 1177/0020764017744581.

42. Chen W, Ling L, Renzaho AM. Building a new life in Australia: an analysis of the first wave of the longitudinal study of humanitarian migrants in Australia to assess the association between social integration and self-rated health. BMJ Open. 2017;7(3): e014313. https://doi.org/10.1136/bmjopen-2016-014313.

43. Ilic B, et al. Mental health in domesticated immigrant population a systematic review. Psychiatr Danub. 2017;29(3):273-81. https:// doi.org/10.24869/psyd.2017.273.

44. Yamanis T, et al. Legal immigration status is associated with depressive symptoms among Latina transgender women in Washington, DC. Int J Environ Res Public Health. 2018;15(6):1246-61. https://doi.org/10.3390/ijerph15061246.

45. Wolf KM, et al. Somali immigrant perceptions of mental health and illness: an ethnonursing study. J Transcult Nurs. 2016;27(4):349-58. https://doi.org/10.1177/1043659614550487.

46. Rusch D, Frazier SL, Atkins M. Building capacity within community-based organizations: new directions for mental health promotion for Latino immigrant families in urban poverty. Adm 
Policy Ment Health. 2015;42(1):1-5. https://doi.org/10.1007/ s10488-014-0549-1.

47. Huang KY, et al. Cultural adaptation, parenting and child mental health among English speaking Asian American immigrant families. Child Psychiatry Hum Dev. 2017;48(4):572-83. https://doi. org/10.1007/s10578-016-0683-y.

48. Straiton ML, et al. Managing mental health problems among immigrant women attending primary health care services. Health Care Women Int. 2016;37(1):118-39. https://doi.org/10.1080/ 07399332.2015.1077844.

49. Thomson MS, et al. Improving immigrant populations' access to mental health services in Canada: a review of barriers and recommendations. J Immigr Minor Health. 2015;17(6):1895-905. https://doi.org/10.1007/s10903-015-0175-3.

50. Cheng ZH, Tu MC, Yang LH. Experiences of social support among Chinese immigrant mental health consumers with psychosis. Community Ment Health J. 2016;52(6):643-50. https:// doi.org/10.1007/s10597-016-0008-4.
51. Chang YQ, et al. Depressive symptoms prevalence and influencing factors among urban and rural elderly patients with chronic diseases. Chin Gen Pract. 2021;24(10):1254-9.

52. He MF. Prevalence and impact of depression symptoms among middle-aged and older Chinese adults with chronic diseases [D]. Ji Lin University. 2019. [Original in Chinese]

53. Jiang YL, et al. Investigation and analysis of psychological status of the elderly with chronic diseases in the community under the background of contracted family doctor services. Chronic Pathematol J. 2020;21(7):966-9.

Publisher's Note Springer Nature remains neutral with regard to jurisdictional claims in published maps and institutional affiliations. 